\title{
Application of Fuzzy-Based Hybrid Taguchi Method for Multiobjective Optimization of Product Form Design
}

\author{
Yongfeng Li $\left(\mathbb{D},{ }^{1}\right.$ Meng-Dar Shieh, ${ }^{2}$ Chih-Chieh Yang, ${ }^{3}$ and Liping Zhu ${ }^{1}{ }^{1}$ \\ ${ }^{1}$ School of Mechanical and Electrical Engineering, Jiangsu Normal University, Xuzhou 221116, China \\ ${ }^{2}$ Department of Industrial Design, National Cheng Kung University, No. 1, University Road, Tainan 70101, Taiwan \\ ${ }^{3}$ Department of Multimedia and Entertainment Science, Southern Taiwan University of Science and Technology, \\ No. 1, Nantai Street, Yungkang District, Tainan 71005, Taiwan
}

Correspondence should be addressed to Yongfeng Li; yflidr@hotmail.com

Received 8 November 2017; Revised 23 June 2018; Accepted 12 July 2018; Published 18 September 2018

Academic Editor: Ibrahim Zeid

Copyright (C) 2018 Yongfeng Li et al. This is an open access article distributed under the Creative Commons Attribution License, which permits unrestricted use, distribution, and reproduction in any medium, provided the original work is properly cited.

In today's competitive market, industrial product form design is moving towards being consumer centric. Affective responses relate to customers' affective needs and are receiving increasing attention. To design a product form that can appeal to consumers, designers should consider multiple affective responses (MARs). This paper proposes a robust design approach that uses a fuzzybased hybrid Taguchi method to derive the optimal product form design concerning MARs. First, design analysis is used to identify design variables and MARs. According to the results, a Taguchi experiment is designed in which fuzzy sets are used to measure the MARs; then, signal-to-noise (S/N) ratios are calculated. Subsequently, a fuzzy questionnaire with multiple answers is employed to acquire consumers' preference weights for MARs, following which Vlsekriterijumska Optimizacija I Kompromisno Resenje (VIKOR) is adopted to transform the multiple $\mathrm{S} / \mathrm{N}$ ratios into a multiperformance characteristic index (MPCI). On the basis of the MPCI, the effects of design variables are identified through analysis of variance and the response table and the response graph are obtained. Consequently, the optimal form design is achieved. A car profile design was used as an example to demonstrate the proposed approach. The results indicate that this approach can effectively improve consumers' affective response qualities and can be used as a robust design approach to optimize product form design.

\section{Introduction}

To survive in a highly competitive market, companies should design products that meet the needs of consumers. As a reflection of the affective needs of consumers on industrial product form, affective responses, which encompass consumers' psychological feelings as well as physiological issues, have received considerable attention from academia and industry [1]. Affective engineering, also called Kansei engineering, is a consumer centric technique for product design that aims to translate affective responses into design variables [2]. Many studies have been performed on optimizing product form design by using affective engineering [3-5]. In these studies, a questionnaire was commonly used to collect evaluation data, and only the mean scale rating was adopted [6]. On the basis of these data, the relationship between design variables and affective responses can be constructed, and the optimal design can then be determined. Nevertheless, evaluations of affective responses are individualistic and subjective, and adopting a mean scale rating alone without considering variations in the evaluations is inappropriate.

A robust design focuses on reducing quality variation and bringing the mean closer to the desired target. The Taguchi method is a robust design approach that adopts many concepts from statistical experiments for optimizing the design of processes or products [7]. In the Taguchi method, "quality" refers to a product's ability to satisfy consumer requirements and expectations [8]. Related studies $[9,10]$ have suggested that the affective response quality significantly influences the desirability of a product and consumer satisfaction. Therefore, affective responses embody 
an aspect of quality that must be considered in product form design $[1,11]$. Several studies have addressed improving the quality of affective responses $[6,12]$.

The quality of affective responses has the features of fuzziness. When measuring affective responses, traditional methods such as semantic differential scales and Likert scales employ numerical values that do not exactly represent a perceptual interpretation because human perceptual interpretation of affective responses involves inherent imprecision or vagueness to a certain extent [13-16]. By contrast, fuzzy sets are a generalization of crisp sets for representing imprecision or vagueness in everyday life, which can serve as a means for modeling the vagueness underlying most natural linguistic terms [17]. Therefore, in many studies, researchers have employed fuzzy sets to subjectively evaluate decision-making processes [18-20]. However, little attention has been devoted to measuring affective responses by using fuzzy sets in the Taguchi method for product form optimization.

The affective responses of humans to products often have various facets. To acquire consumers' preference weights for multiple affective responses (MARs), numerous studies have used questionnaires with single answers [3, 4]. However, as fuzzy statistics scholars have indicated that human thinking cannot be measured or described with a single option [21]. A fuzzy questionnaire with multiple answers can reflect the variability and intricacy of human fuzzy thinking, and the robustness and consistency of the evaluation process can be enhanced by reducing the degree of evaluator subjectivity [22, 23]. From the results of such a fuzzy questionnaire, the final option and the fuzzy thinking of a participant can be determined from fuzzy data; that is, the participant's preferences are reflected more accurately in a fuzzy questionnaire [24]. However, to the best of our knowledge, very few studies have used a fuzzy questionnaire to measure consumers' MARs preferences.

To integrate the performance characteristics of MARs into one performance characteristic according to preference weights, a multicriteria decision-making (MCDM) method is usually required. Vlsekriterijumska Optimizacija I Kompromisno Resenje (VIKOR) was developed by Opricovic [25] for multicriteria optimization of complex systems. It determines a compromise ranking list, a compromise solution, and weight stability intervals for the preference stability of the compromise solution obtained using the initial weights. The obtained compromise solution is very satisfactory because it provides the minimum individual regret for the opponent and the maximum group utility for the majority [26]. Recently, owing to its characteristics and capabilities, the VIKOR method has been employed by many researchers to solve decision-making problems [27]. Thus far, however, few studies have used the VIKOR method in research related to affective responses.

In this paper, the authors propose a fuzzy-based hybrid Taguchi method for optimizing product form design concerning affective responses. In this approach, fuzzy sets are used to measure the affective responses of consumers to a product, and a fuzzy questionnaire is used to collect consumers' preference weights for MARs. Furthermore, the proposed approach uses VIKOR to convert the signal-to-noise
$(\mathrm{S} / \mathrm{N})$ ratios of MARs into a single index called the multiperformance characteristic index (MPCI). Product form design is then optimized on the basis of the MPCI. The remainder of this paper is organized as follows. Section 2 presents the relevant theoretical research background. Section 3 describes the proposed approach. Section 4 presents a case study, the results of which are discussed in Section 5. Finally, Section 6 provides a few concluding remarks.

\section{Theoretical Background}

2.1. Taguchi Method. The Taguchi method is a simple, efficient, and systematic quality improvement method that has been used to achieve robustness in many fields, including materials science [28], mechanical engineering [29], and usability engineering [30]. It can be used to derive optimal processes and products, as well as to identify the control factors that significantly influence a particular quality characteristic [31]. The Taguchi method involves two major tools: the orthogonal array (OA) and $\mathrm{S} / \mathrm{N}$ ratio [32].

The OA is a fractional factorial matrix that can balance any factor and interactions among the factors, and it forms the basis of experimental design. For product form design by using classical experimental methods, numerous experimental samples must be considered when the number of design variables is high. To solve this problem, the Taguchi method employs the OA to study the entire design variable space by using only a few experimental samples. The $\mathrm{S} / \mathrm{N}$ ratio is used as a quality characteristic that can be analyzed using analysis of variance (ANOVA) to ascertain both the effects of the design variables and the contribution percentage of each design variable. In addition, on the basis of $\mathrm{S} / \mathrm{N}$ ratios, a response table and a response graph can be derived and, then, the optimal design can be determined.

The original Taguchi method was designed to optimize a single performance characteristic, and it has successfully been applied in various fields. However, it fails to optimize multiple performance characteristics [33]. Therefore, a hybrid approach is required to solve multiobjective optimization problems [10]. Affective responses of humans to products have multiple aspects and, thus, optimizing the quality of affective responses is a multiobjective problem. In this study, the authors propose a fuzzy-based hybrid Taguchi method to optimize product form design, and this method employs VIKOR as an MCDM method to integrate the $\mathrm{S} / \mathrm{N}$ ratios of MARs into one quality characteristic for single-objective optimization.

2.2. Fuzzy Set Theory. Fuzzy set theory, developed by Zadeh [34], is a powerful tool for managing concepts and rules that involve uncertainty, imprecision, and nonlinearity. This theory is based on the premise that the key points of human thinking are not numbers but linguistic terms or labels of fuzzy sets. In fuzzy set theory, fuzzy numbers can be used to efficiently represent knowledge and to measure affective responses by using linguistic terms [13]. There are many types of fuzzy numbers, such as triangular, trapezoidal, sigmoid, and Gaussian. Triangular fuzzy numbers are intuitive, simple to calculate, and easy to understand and can well express 
multiple linguistic variables [35]; therefore, in this study, triangular fuzzy numbers were used to measure affective responses.

One of the most important concepts of fuzzy set theory is the alpha cut. The alpha cut of a fuzzy set $\widetilde{A}$ of the universal set $X$ can be defined as [36]

$$
\widetilde{A}(\alpha)=\left\{x \in X \mid \mu_{\widetilde{A}}(x) \geq \alpha\right\}, \quad \forall \alpha \in[0,1] .
$$

Clearly, the alpha cut of a fuzzy set $\widetilde{A}$ is the crisp set that contains all elements of the universal set $X$ whose membership grades in $\widetilde{A}$ are greater than or equal to the specified alpha value [37].

In this study, fuzzy sets have been used to measure consumers' MARs preferences, and the alpha cut has been used to calculate the $\mathrm{S} / \mathrm{N}$ ratios. In addition, a fuzzy questionnaire with multiple answers has been employed to acquire consumers' MARs preferences.

2.3. VIKOR. The VIKOR method focuses on ranking and sorting a set of alternatives against various, possibly conflicting, criteria. The method employs a ranking index based on a particular measure of "closeness" to the "ideal" solution [36]. Given that each alternative is evaluated according to each criterion, compromise ranking of an alternative can be performed by comparing its measure of closeness to the ideal alternative. The multicriteria measure for compromise ranking is developed from the $L_{p}$ metric. For an alternative $a_{i}$, the rating of the $j$ th criterion is denoted by $f_{i j}$ and the $L_{p}$ metric can be defined as follows:

$$
L_{p, i}=\left\{\sum_{j=1}^{n}\left[\frac{w_{j}\left(f_{j}^{*}-f_{i j}\right)}{\left(f_{j}^{*}-f_{j}^{-}\right)}\right]^{p}\right\}^{1 / p},
$$

where $1 \leq p \leq \infty$ and $i=1,2, \cdots, m$.

Within the VIKOR method, the utility function is an aggregate of $L_{1, i}$ and $L_{\infty, i} . L_{1, i}$ is interpreted as "concordance," and it can provide decision-makers with information about the maximum "group utility" or "majority." $L_{\infty, i}$ is interpreted as "discordance," and it provides decision-makers with information about the minimum individual regret of the "opponent."

The VIKOR method has the following unique characteristics [38]. (1) The best alternatives determined using the VIKOR method are the closest to the ideal solution and the farthest from the negative ideal solution. (2) The best alternative determined using the VIKOR method ensures the maximum group utility and the least regret from the viewpoint of decision-makers. (3) The VIKOR method considers two distance measurements, $L_{1, i}$ and $L_{\infty, i}$, based on the $L_{p}$ metric to provide information about utility and regret. (4) The VIKOR method considers two weights in decision-making-one pertaining to the criteria and the other pertaining to the maximum group utility. Owing to these characteristics, the VIKOR method can be effectively used as a synthetic index for MCDM. Thus, VIKOR has been used to integrate multiple quality characteristics into one quality characteristic.

\section{Proposed Approach}

The authors propose a structured, generic approach that integrates the Taguchi method with fuzzy set theory and VIKOR to optimize product form design in terms of MARs. This approach comprises four stages: (1) design analysis, (2) Taguchi experiment, (3) transformation of $\mathrm{S} / \mathrm{N}$ ratios, and (4) optimization design. Figure 1 illustrates a systematic flowchart of the proposed approach.

3.1. Design Analysis. The first stage is design analysis, and it involves product form analysis and affective response analysis. Product form analysis aims to clarify the character of form to ascertain design variables that are usually discrete, such as the type of design components $[1,9]$. In the analysis of affective responses, adjectives are used to describe one's affective responses to a product [2], and factor analysis is then used to identify the affective factors underlying these adjectives.

3.2. Taguchi Experiment. After ascertaining the design variables and affective responses, the Taguchi experiment is designed, where the design variables are considered as control factors and the affective factors are considered as quality characteristics. On the basis of the design variables and their levels, the total degrees of freedom (DOFs) can be calculated. Subsequently, an OA is selected carefully to fit the specific task. The DOFs of the OA should be not less than those of the design variables [32].

The quality characteristics can be classified into three types, namely, larger-the-better (LTB), smaller-the-better (STB), and nominal-the-better (NTB), and their S/N ratios can be calculated by using (3), (4), and (5), respectively,

$$
\begin{aligned}
& \left(\frac{S}{N}\right)_{L T B}=-10 \log _{10}\left(\frac{1}{n} \sum_{i=1}^{n} \frac{1}{y_{i}^{2}}\right), \\
& \left(\frac{S}{N}\right)_{S T B}=-10 \log _{10}\left(\frac{1}{n} \sum_{i=1}^{n} y_{i}^{2}\right), \\
& \left(\frac{S}{N}\right)_{N T B}=10 \log _{10}\left(\frac{\bar{y}^{2}}{S_{d}^{2}}\right),
\end{aligned}
$$

where $y_{i}$ is the measured property that refers to affective responses in this study, $n$ is the number of tests for one experimental sample, $\bar{y}$ is the mean of the measured property, and $S_{d}$ is the standard deviation.

To measure the quality performance of the affective responses, a triangular fuzzy number $\widetilde{A}=\left(a_{1}, a_{2}, a_{3}\right)$ is used, and it is defined as follows:

$$
\mu_{\widetilde{A}}(x)= \begin{cases}0, & x<a_{1} \\ \frac{\left(x-a_{1}\right)}{\left(a_{2}-a_{1}\right)}, & a_{1} \leq x \leq a_{2} \\ \frac{\left(a_{3}-x\right)}{\left(a_{3}-a_{2}\right),} & a_{2} \leq x \leq a_{3} \\ 0, & x>a_{3},\end{cases}
$$




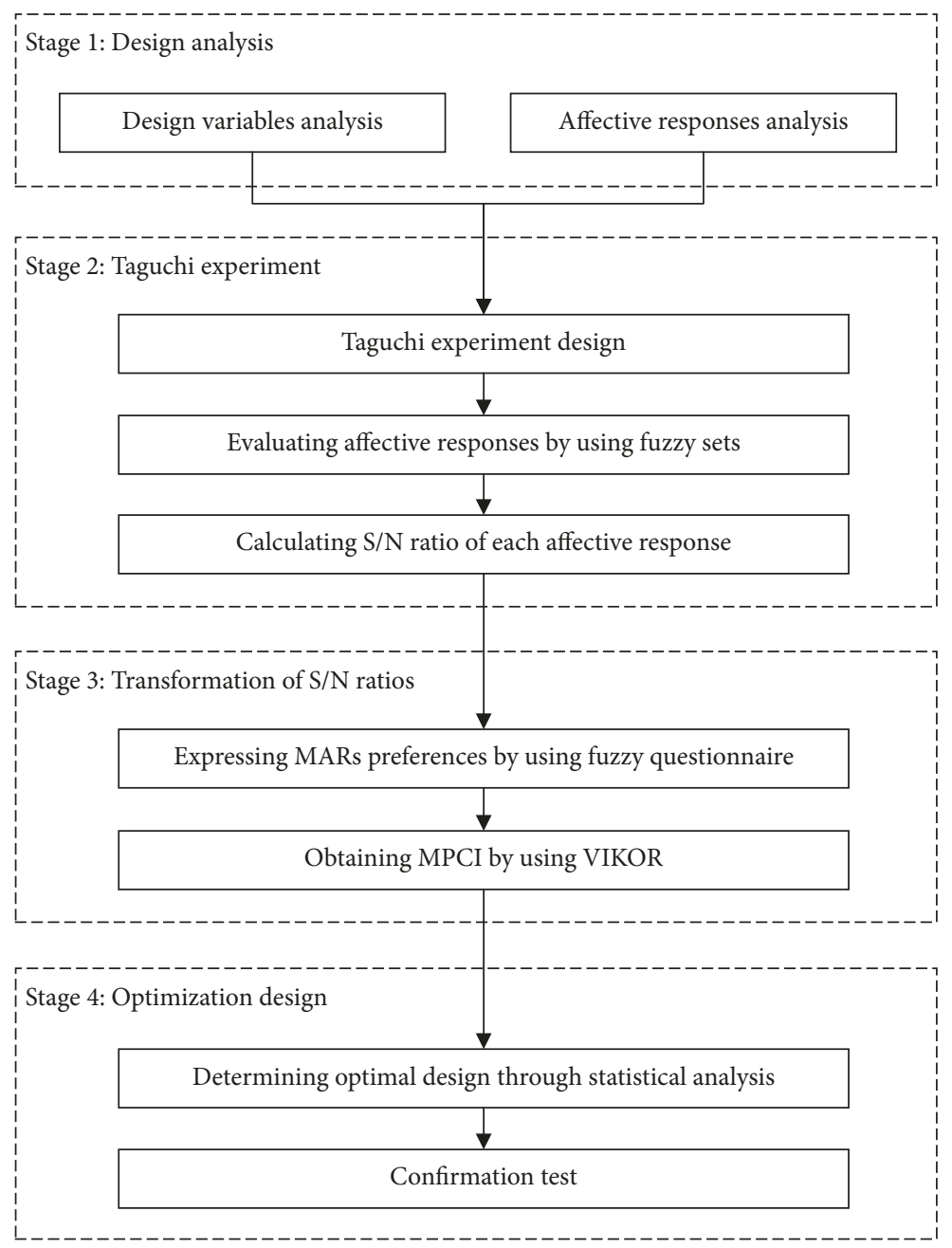

FIGURE 1: Framework of proposed approach.

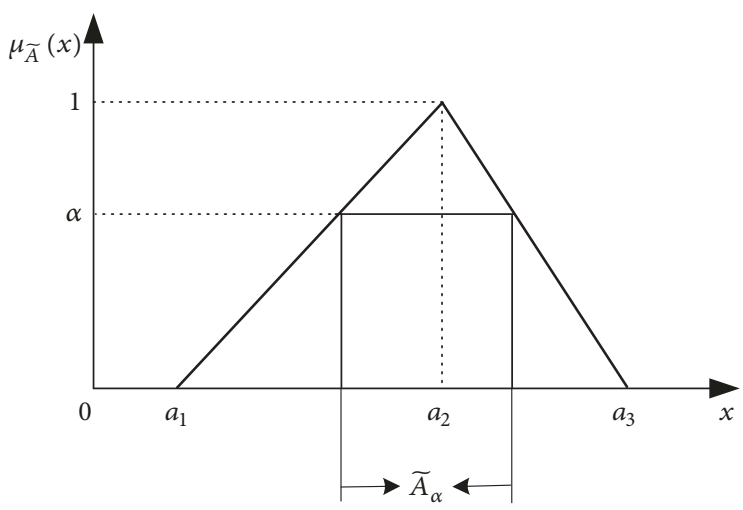

FIGURE 2: Illustration of alpha cut for triangular fuzzy numbers.

where $\mu_{\widetilde{A}}$ is the membership function; $x$ is a variable; and $a_{1}$, $a_{2}$, and $a_{3}$ are parameters. Computing the $\mathrm{S} / \mathrm{N}$ ratios by using fuzzy numbers may involve the arithmetic operations of multiplication and division. Because the results of the arithmetic addition and subtraction of triangular fuzzy numbers are triangular fuzzy numbers as well, whereas those of arithmetic multiplication and division of triangular fuzzy numbers may not be triangular fuzzy numbers $[18,37]$, alpha cuts were used to calculate the $\mathrm{S} / \mathrm{N}$ ratios of different alpha levels. The alpha cut of a triangular fuzzy number is illustrated in Figure 2 and calculated according to

$$
\widetilde{A}_{\alpha}=\left[a_{1}+\left(a_{2}-a_{1}\right) \alpha, a_{3}-\left(a_{3}-a_{2}\right) \alpha\right] .
$$

To derive the crisp output of the $\mathrm{S} / \mathrm{N}$ ratio, defuzzification is necessary, and it can be performed using a few methods, including center of gravity (COG), center of area, and mean of maxima. Among these methods, COG, which has a distinct geometrical meaning, is the most precise and widely used method [39]. Therefore, in the present study, the COG method has been adopted for defuzzification, and it is expressed as follows:

$$
S N=\frac{\sum S N_{i} \times\left[\mu\left(S N_{i}\right)\right]}{\sum\left[\mu\left(S N_{i}\right)\right]},
$$

where $S N$ is the crisp value of $\mathrm{S} / \mathrm{N}$ ratios, $\mu\left(S N_{i}\right)$ is the $i$ th alpha level, and $S N_{i}$ is the $S / N$ ratio of the $i$ th alpha level. 
3.3. Transformation of $S / N$ Ratios. The $S / N$ ratio of one affective response is inappropriate for optimizing MARs because a high $\mathrm{S} / \mathrm{N}$ ratio for one affective response can lead to low $\mathrm{S} / \mathrm{N}$ ratio for another affective response, and vice versa. Thus, the authors have presented a method that combines a fuzzy affective response questionnaire and VIKOR to transform the multiobjective optimization problem relevant to MARs into an equivalent single-objective optimization problem.

3.3.1. Expressing MARs Preferences by Using Fuzzy Questionnaire. To represent the values of MARs preferences, the authors have used a fuzzy questionnaire with multiple answers that can help consumers express their preferences accurately. When analyzing the fuzzy questionnaire, the fuzzy sample mean is required, and it is defined as follows [21].

Let $U$ be the universal set, $L=\left\{L_{1}, L_{2}, \cdots, L_{k}\right\}$ be a set of $k$-linguistic variables in $U$, and $\left\{F x_{i}=m_{i 1} / L_{1}+m_{i 2} / L_{2}+\right.$ $\left.\cdots+m_{i k} / L_{k}, i=1,2, \cdots, n\right\}$ be a sequence of random fuzzy samples in $U . m_{i j}$ is the membership with respect to $L_{j}$, and $\sum_{j=1}^{k} m_{i j}=1$. Then, the fuzzy sample mean can be expressed as

$$
\begin{aligned}
F \bar{x}= & \frac{(1 / n) \sum_{i=1}^{n} m_{i 1}}{L_{1}}+\frac{(1 / n) \sum_{i=1}^{n} m_{i 2}}{L_{2}}+\cdots \\
& +\frac{(1 / n) \sum_{i=1}^{n} m_{i k}}{L_{k}} .
\end{aligned}
$$

To derive consumers' preference weights for MARs, the fuzzy relative weight (FRW) is employed, and it is defined as follows [24].

Consider the universe of discourse $S=\left\{S_{1}, S_{2}, \ldots, S_{K}\right\}$, utility sequence $r=\left\{r_{1}, r_{2}, \cdots, r_{f}\right\}$, and $\mu_{S_{i} f}$ as the membership function of $r_{j}$ in $S_{i}$. Then, the fuzzy relative weight $F R W=\left(F R W_{S_{1}}, F R W_{S_{2}}, \ldots, F R W_{S_{k}}\right)$ can be calculated as

$$
F R W_{S_{i}}=\frac{\sum_{l=1}^{f} l \cdot \mu_{S_{i} l}}{\sum_{i=1}^{k} \sum_{l=1}^{f} l \cdot \mu_{S_{i} l}},
$$

where $r_{1}<r_{2}<\cdots<r_{f}$ (usually $r_{1}=1, r_{2}=2, \ldots, r_{f}=f$ ) and $i=1,2, \ldots, m$.

3.3.2. Obtaining MPCI by Using VIKOR. The VIKOR method has been employed to convert the $\mathrm{S} / \mathrm{N}$ ratios into an MPCI value through the following steps [26].

Step 1. Normalize the decision matrix of $\mathrm{S} / \mathrm{N}$ ratios.

The $\mathrm{S} / \mathrm{N}$ ratio of an experimental sample is normalized as follows:

$$
f_{i j}=\frac{x_{i j}}{\sqrt{\sum_{i=1}^{m} x_{i j}^{2}}}
$$

where $x_{i j}$ is the $\mathrm{S} / \mathrm{N}$ ratio of experimental sample $A_{i}$ with respect to the $j$ th performance characteristic; $f_{i j}$ is the normalized $\mathrm{S} / \mathrm{N}$ ratio; $i=1,2, \ldots, m$; and $j=1,2, \ldots, n$. Then, the normalized decision matrix can be represented as follows:

$$
F=\left[f_{i j}\right]_{m \times n} .
$$

Step 2. Determine the ideal and negative ideal solutions.

The ideal solution $A^{*}$ and the negative ideal solution $A^{-}$ are determined as follows:

$$
\begin{aligned}
A^{*} & =\left\{\left(\max f_{i j} \mid j \in J\right) \operatorname{or}\left(\min f_{i j} \mid j \in J^{\prime}\right) \mid i\right. \\
& =1,2, \cdots, m\}=\left\{f_{1}^{*}, f_{2}^{*}, \cdots, f_{n}^{*}\right\}, \\
A^{-} & =\left\{\left(\min f_{i j} \mid j \in J\right) \operatorname{or}\left(\max f_{i j} \mid j \in J^{\prime}\right) \mid i\right. \\
& =1,2, \cdots, m\}=\left\{f_{1}^{-}, f_{2}^{-}, \cdots, f_{n}^{-}\right\},
\end{aligned}
$$

where $J=\left\{j=1,2, \cdots, n \mid f_{i j}\right.$, a large response is desired $\}$ and $J^{\prime}=\left\{j=1,2, \cdots, n \mid f_{i j}\right.$, a small response is desired $\}$.

Step 3. Compute the utility measure and the regret measure.

The utility measure and the regret measure for each alternative are computed as follows:

$$
\begin{aligned}
& S_{i}=\sum_{j=1}^{n} \frac{w_{j}\left(f_{j}^{*}-f_{i j}\right)}{\left(f_{j}^{*}-f_{j}^{-}\right)}, \\
& R_{i}=\max _{j}\left[\frac{w_{j}\left(f_{j}^{*}-f_{i j}\right)}{\left(f_{j}^{*}-f_{j}^{-}\right)}\right],
\end{aligned}
$$

where $S_{i}$ and $R_{i}$ represent the utility measure and the regret measure, respectively, and $w_{j}$ is the preference weight of the $j$ th affective response performance characteristic.

Step 4. Calculate the MPCI value.

The VIKOR index is taken as the MPCI value, which is expressed as follows:

$$
Q_{i}=v\left[\frac{S_{i}-S^{*}}{S^{-}-S^{*}}\right]+(1-v)\left[\frac{R_{i}-R^{*}}{R^{-}-R^{*}}\right],
$$

where $Q_{i}$ represents the MPCI value of the $i$ th alternative and $i=1,2, \cdots, m ; S^{*}=\min _{i} S_{i}, S^{-}=\max _{i} S_{i}, R^{*}=\min _{i} R_{i}$, and $R^{-}=\max _{i} R_{i}$; and $v$ is the weight of the maximum group utility, which is usually set to 0.5 .

Step 5. Rank the experimental sample.

The experimental sample with the smallest MPCI value is determined to be the best solution, and it is assigned an order of 1 .

3.4. Optimization Design. This stage involves identifying the significant design variables and deriving the optimal design. In the Taguchi method, the objective is to maximize the $\mathrm{S} / \mathrm{N}$ ratio to minimize variability in the quality characteristics and to maximize the mean quality characteristics. When multiple $\mathrm{S} / \mathrm{N}$ ratios are transformed into a single MPCI value by using the VIKOR method, it is desirable to minimize the MPCI. On the basis of the MPCI, ANOVA can be applied to identify the significant design variables.

The response table and the response graph, which can be determined from the response values, are used to derive the 
optimal design. The response value for each type of design variable can be calculated as follows:

$$
R_{i}=\frac{\sum_{i=1}^{m} \eta_{i}}{m}
$$

where $R_{i}$ is the response value, $\eta_{i}$ is the MPCI value of a design variable with the same level, and $m$ is the number of experimental samples with the same level of the design variable. The smaller the MPCI, the better the multiple performance characteristics are. Therefore, the optimal design can be identified by determining the smallest MPCI among all possible combinations of the design variables.

The final step is to verify the performance of the optimized product form design. After a confirmation experiment involving the original and the optimal designs is executed, the evaluation values for MARs can be obtained. On the basis of these values, the S/N ratios and the MPCI can be calculated. Finally, the quality performances are compared to verify the obtained optimal design.

\section{Case Study}

A car is a typical example of a mature product. As a concentrated expression of car form design, car profile has been receiving increasing attention in car selection by consumers, and much research has been devoted to it $[1,9,10,40]$. Therefore, in this study, a car profile was adopted as a case study to demonstrate the proposed approach.

4.1. Design Analysis for Car Profile. A total of 120 profile images of cars currently available in the market were collected. These images were reviewed by a focus group comprising seven car design experts, and morphological analysis was used to construct the design variables that influenced affective responses. These design variables were classified into two categories: one related to the form of different profile parts, as listed in Table 1 and the other related to the ratios of different profile parts that also contributed significantly to the affective responses, as listed in Table 2 . The design variables $\mathrm{F}$ (ratio of car height to car length), $\mathrm{H}$ (ratio of wheel height to car height), and L (ratio of front overhang length to car length) and their corresponding levels were adopted from Chang and Chen [9].

In total, 258 affective adjectives were collected from the academic literature, car magazines, and car company websites. Among them, 20 words were selected as the most relevant to car design. Factor analysis was employed to investigate the factor structure of these words. The 20 affective words were then grouped into four main factors, which accounted for $92.752 \%$ of the cumulative variance. The four factors were "Modern," "Comfortable," "Rounded," and "Simple." These factors were used as the basis for determining the quality characteristics of affective responses.

\subsection{Taguchi Experiment for Car Profile Design}

4.2.1. Taguchi Experiment Design. In this study, 13 design variables with three levels were investigated; therefore, the number of possible design combinations was $1,594,323\left(3^{13}\right)$, which was too large to prepare experimental samples for the affective response experiment. To reduce the number of experimental samples, OA was adopted. Only the main effects were of interest, and interactions between design variables were not studied. The number of DOFs of each design variable was 2 (number of levels minus 1); thus, the total number of DOFs was $26(13 \times 2)$. The experimental design followed an $L_{27} \mathrm{OA}$, and the design layout is presented in Table 3. Overall, 27 combinative designs were employed as the experimental samples, as shown in Figure 3.

4.2.2. Evaluating Affective Responses by Using Fuzzy Sets. In this study, 60 graduates ( 30 women and 30 men, 22-30 years of age) from a university were invited to the industrial design laboratory as experimental participants. Young participants were recruited because young consumers seeking to buy a car usually focus more on car form than those in other age groups do. The experiment was conducted according to the Taguchi experiment design by administering a questionnaire. The questionnaire was composed by combining the 27 experimental samples with the four affective factors, which were rated using five fuzzy linguistic terms, namely, very low (VL), low (L), medium (M), high (H), and very high (VH). Triangular fuzzy numbers were used to represent these five terms, and the corresponding membership functions are shown in Figure 4.

4.2.3. Calculating S/N Ratio of Each Affective Response. Fuzzy sets were used to measure the affective responses. The larger the degree of membership of a characteristic, the higher the UX quality is. Therefore, all quality characteristics fit under the larger-the-better scheme. Thus, the $\mathrm{S} / \mathrm{N}$ ratios must be computed using (3). Because calculating the $\mathrm{S} / \mathrm{N}$ ratios involves the arithmetic operations of multiplication and division of triangular fuzzy numbers, alpha cuts were used to compute the $\mathrm{S} / \mathrm{N}$ ratios. For different alpha levels, the corresponding reciprocals of the squares of the alpha cuts were calculated. The evaluation results of all participants were then integrated according to the reciprocals. On the basis of the integrated values, the $\mathrm{S} / \mathrm{N}$ ratios were obtained. For example, for the fuzzy linguistics term medium (M), by substituting the alpha levels of $0,0.100,0.200, \ldots$, and 1.000 into (7), the alpha cuts were calculated; then, the corresponding reciprocals of the squares of the alpha cuts were determined, as shown in Table 4. By integrating the results of the 60 participants for experimental sample No. 1 concerning affective response of "Modern," the $\mathrm{S} / \mathrm{N}$ ratios related to different alpha levels were calculated, as shown in Table 5 and Figure 5. Subsequently, by using (8) for defuzzification, the $\mathrm{S} / \mathrm{N}$ ratio value of 11.774 was obtained. Thus, the $\mathrm{S} / \mathrm{N}$ ratios of all the experimental samples related to the affective responses of "Modern," "Comfortable," "Rounded," and "Simple" were derived, and the results are listed in columns $2-5$ of Table 6.

\subsection{Transformation of S/N Ratios for Car Profile Design}

4.3.1. Expressing MARs Preferences. A fuzzy affective response questionnaire with multiple answers was administered to the 60 participants for acquiring their MARs 
TABLE 1: Design variables for car form.

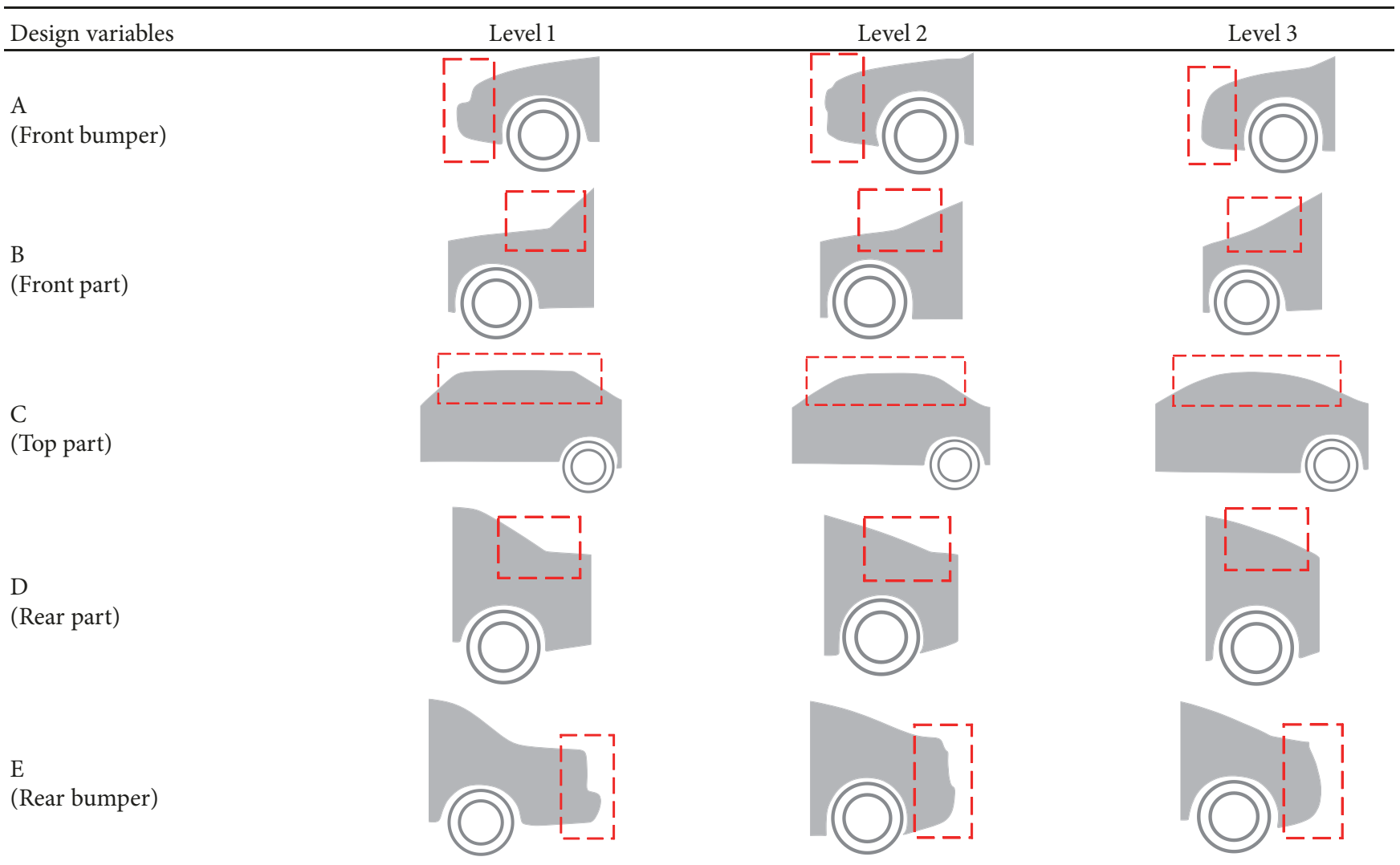

preferences. There were five linguistic labels in this questionnaire, namely, very unimportant (VU), not important $(\mathrm{NI})$, neutral $(\mathrm{N})$, important (I), and very important (VI). By using this questionnaire, the participants could express their MARs preferences accurately, as illustrated in Table 7. After collecting the preferences of all the participants, (9) is used to determine the fuzzy sample mean, and the results are summarized in Table 8. Subsequently, by using (10), the preference weights for "Modern," "Comfortable," "Rounded," and "Simple" were obtained as $0.313,0.254,0.156$, and 0.277, respectively.

4.3.2. Obtaining MPCI. By using VIKOR, the $\mathrm{S} / \mathrm{N}$ ratios of the affective response characteristics were transformed into MPCI values based on the preference weights. Initially, the $\mathrm{S} / \mathrm{N}$ ratios were normalized by substituting them into (11). Next, by combining (12), (13), and (14), the ideal solution and the negative ideal solution were obtained. Subsequently, by substituting these solutions and preference weights into (15) and (16), the utility measure and the regret measure were obtained, respectively, and by incorporating these values into (17), the MPCI value (i.e., VIKOR index) was computed. Finally, by using the MPCI value, the experimental samples were ranked. The MPCI value and the corresponding ranks are listed in columns 6 and 7 of Table 6.

\subsection{Optimizing Car Profile Design}

4.4.1. Determining Optimal Design through Statistical Analysis. ANOVA was employed to identify the significant design variables and to determine the contribution percentage of each design variable to the MPCI. When pooling the errors, the authors followed the Taguchi recommendation of pooling the design variables until the error DOFs were approximately half the total DOFs of the experiment [41]. Table 9 shows the ANOVA results for the MPCI, and the results clearly indicate that the design variables $\mathrm{C}$ (Top part), $\mathrm{F}$, and $\mathrm{K}$ (Ratio of rear part length to car length) significantly influence the MPCI. In addition, the design variable $\mathrm{F}$ is the most significant because it has the highest contribution percentage among the design variables.

The relative effects among the design variables determined through ANOVA can be verified by referring to the response table and the response graph. The ANOVA, response table, and response graph provide valuable design insights. The response value for each level of the design variables was computed by using (18), and the results are listed in Table 10. Delta indicates the difference between the maximum and minimum responses. The design variables were ranked according to these delta values, with 1 being the largest value. The total average MPCI of the 27 experimental samples was 0.420 . Figure 6 shows the response graph, where 
TABLE 2: Design variables for car ratio.

\begin{tabular}{|c|c|c|c|c|}
\hline Design variables & Diagrammatic sketch & Level 1 & Level 2 & Level 3 \\
\hline $\begin{array}{l}\text { F } \\
\text { (Ratio of car height to car } \\
\text { length, H1/L1) }\end{array}$ & & 0.32 & 0.37 & 0.42 \\
\hline $\begin{array}{l}\text { G } \\
\text { (Ratio of car top part to car } \\
\text { height, } \mathrm{H} 2 / \mathrm{H} 1 \text { ) }\end{array}$ & & 0.27 & 0.30 & 0.33 \\
\hline $\begin{array}{l}\mathrm{H} \\
\text { (Ratio of wheel height to } \\
\text { car height, H3/H1) }\end{array}$ & & 0.40 & 0.45 & 0.50 \\
\hline $\begin{array}{l}\text { I } \\
\text { (Ratio of chassis height to } \\
\text { wheel height, H4/H3) }\end{array}$ & & 0.20 & 0.35 & 0.50 \\
\hline $\begin{array}{l}\text { J } \\
\text { (Ratio of fore part length to } \\
\text { car length, L2/L1) }\end{array}$ & & 0.18 & 0.24 & 0.30 \\
\hline $\begin{array}{l}\text { K } \\
\text { (Ratio of rear part length to } \\
\text { car length, L3/L1) }\end{array}$ & & 0.09 & 0.13 & 0.17 \\
\hline $\begin{array}{l}\text { L } \\
\text { (Ratio of front overhang } \\
\text { length to car length, L4/L1) }\end{array}$ & & 0.14 & 0.18 & 0.22 \\
\hline $\begin{array}{l}\text { M } \\
\text { (Ratio of rear overhang } \\
\text { length to car length, L5/L1) }\end{array}$ & & 0.17 & 0.20 & 0.23 \\
\hline
\end{tabular}

the dashed line indicates the total average MPCI. Clearly, the design variable $\mathrm{F}$ has the strongest effect on the MPCI, followed by the design variables $\mathrm{C}, \mathrm{K}$, and $\mathrm{G}$ (ratio of car top part to car height). Furthermore, the design variable I (Ratio of chassis height to wheel height) has the weakest influence on the MPCI.

The optimal levels of design variables were determined on the basis of a smaller VIKOR value indicating higher quality. Therefore, according to the response table and the response graph, the derived optimal level combination, that is, the optimal design, was $\mathrm{A}_{3} \mathrm{~B}_{3} \mathrm{C}_{3} \mathrm{D}_{3} \mathrm{E}_{1} \mathrm{~F}_{1} \mathrm{G}_{2} \mathrm{H}_{2} \mathrm{I}_{3} \mathrm{~J}_{2} \mathrm{~K}_{1} \mathrm{~L}_{1} \mathrm{M}_{3}$.

4.4.2. Confirmation Test. The identified optimal design based on MARs was not found in the $L_{27}$ OA. Therefore, a confirmation test was executed to verify the improvement in performance characteristics. The 60 participants were asked to evaluate the optimal design obtained using the proposed approach, a competitor's design, and the initial design in the OA (Sample No. 1). Table 11 presents a comparison of the three car profile designs. The total $\mathrm{S} / \mathrm{N}$ ratios of the four MARs increased from 41.051 for the initial design to 62.651 for the optimal design, an improvement of 21.600. The total $\mathrm{S} / \mathrm{N}$ ratios increased from 59.532 for the competitor's design to 62.651 for the optimal design, an improvement of 3.119; moreover, the $\mathrm{S} / \mathrm{N}$ ratios of all MARs for the optimal design are greater than those for the competitor design. The obtained optimal product form design is clearly effective; therefore, the proposed approach is valid and feasible. 


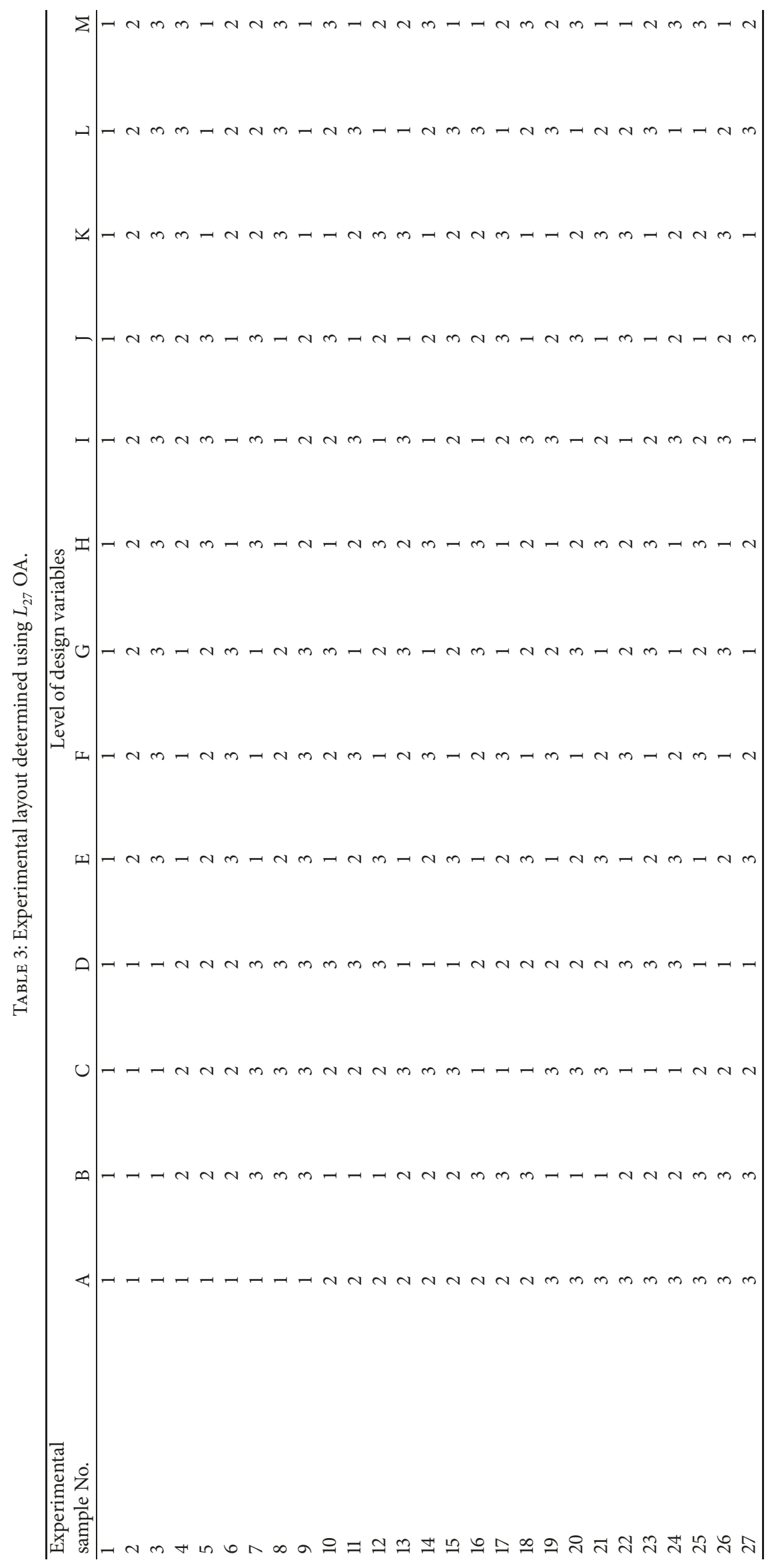




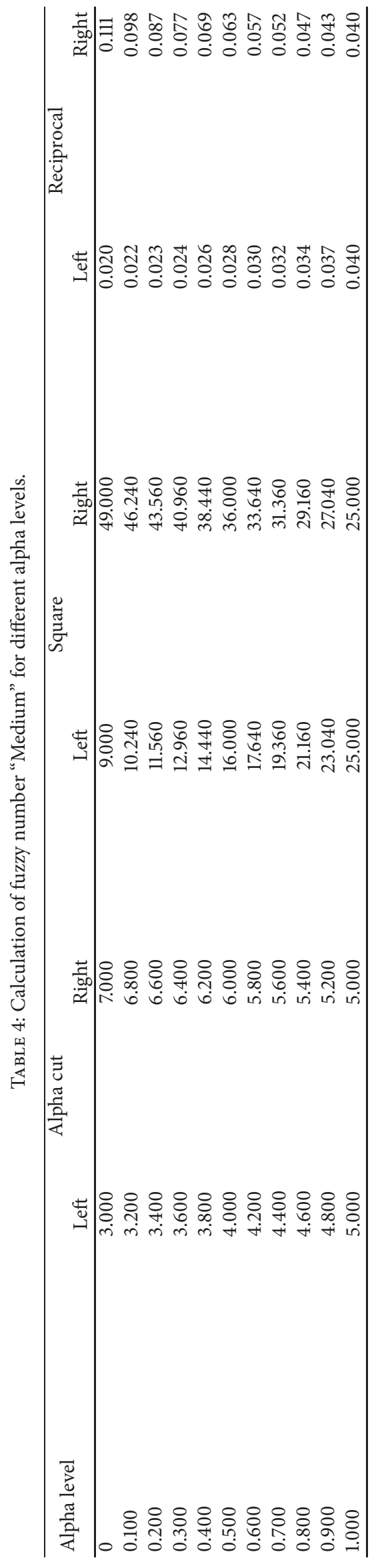


TABLE 5: Calculation of $\mathrm{S} / \mathrm{N}$ ratios for different alpha levels.

\begin{tabular}{lcccc}
\hline \multirow{2}{*}{ Alpha level } & \multicolumn{2}{c}{ Integration of reciprocals } & \multicolumn{2}{c}{ S/N ratio (dB) } \\
& Left & Right & Left & 5.116 \\
\hline 0 & 1.306 & 9.729 & 15.450 & 6.188 \\
0.100 & 1.383 & 7.968 & 15.169 & 7.120 \\
0.200 & 1.468 & 6.694 & 14.878 & 7.945 \\
0.300 & 1.562 & 5.734 & 14.574 & 8.683 \\
0.400 & 1.667 & 4.986 & 14.257 & 9.353 \\
0.500 & 1.782 & 4.389 & 13.926 & 9.965 \\
0.600 & 1.912 & 3.902 & 13.579 & 10.529 \\
0.700 & 2.057 & 3.499 & 13.214 & 11.052 \\
0.800 & 2.222 & 3.159 & 12.830 & 11.539 \\
0.900 & 2.409 & 2.871 & 12.425 & 11.996 \\
1.000 & 2.623 & 2.623 & 11.996 & \\
\hline
\end{tabular}

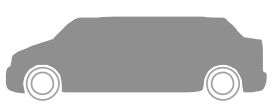

1

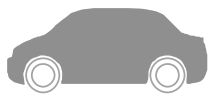

6

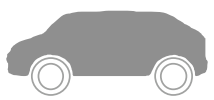

11

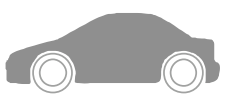

16

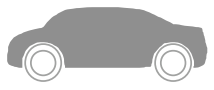

21

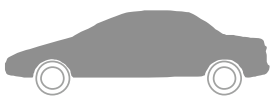

26

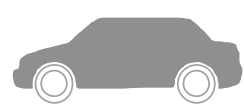

2

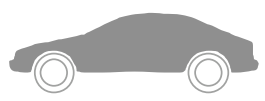

7

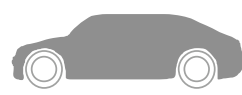

12

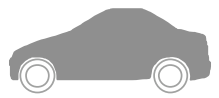

17

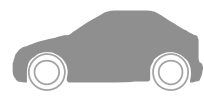

22

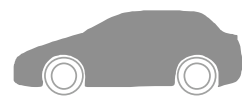

27

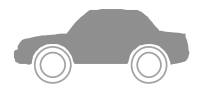

3
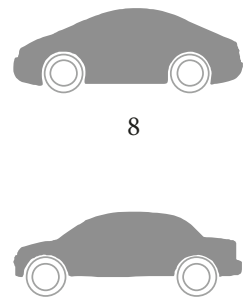

13

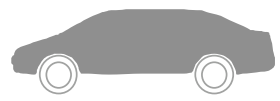

18

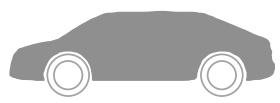

23

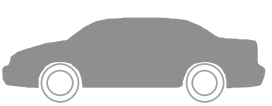

4

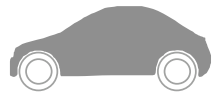

9

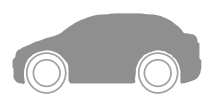

14

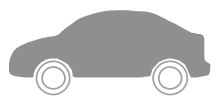

19

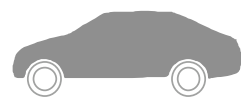

24

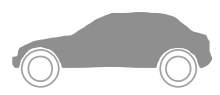

5

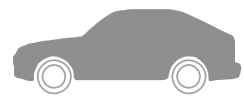

10

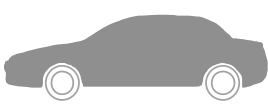

15

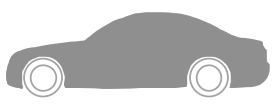

20

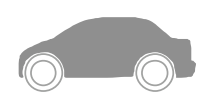

25

FIgURE 3: Twenty-seven combinative designs used in Taguchi experiment.

\section{Discussion}

In this study, to obtain the optimal product form design related to MARs, a fuzzy-based hybrid Taguchi method is proposed to derive robust parameter settings. Execution of the proposed method was demonstrated using a case study involving the design of a car profile. Only the main effects of the design variables were considered; no attempt was made to analyze the interactions among the design variables. In the Taguchi OA, the effects of interactions are mixed with the main effect of a design variable assigned to some other column [32]. Therefore, if the interactions among the design variables is to be included, a suitable OA must be selected according to the specific design problem.

Note that the design variables and their corresponding levels can be changed according to the products available on the market and the research focus. The aim of this study is to present a new approach and, thus, a few aspects of the 


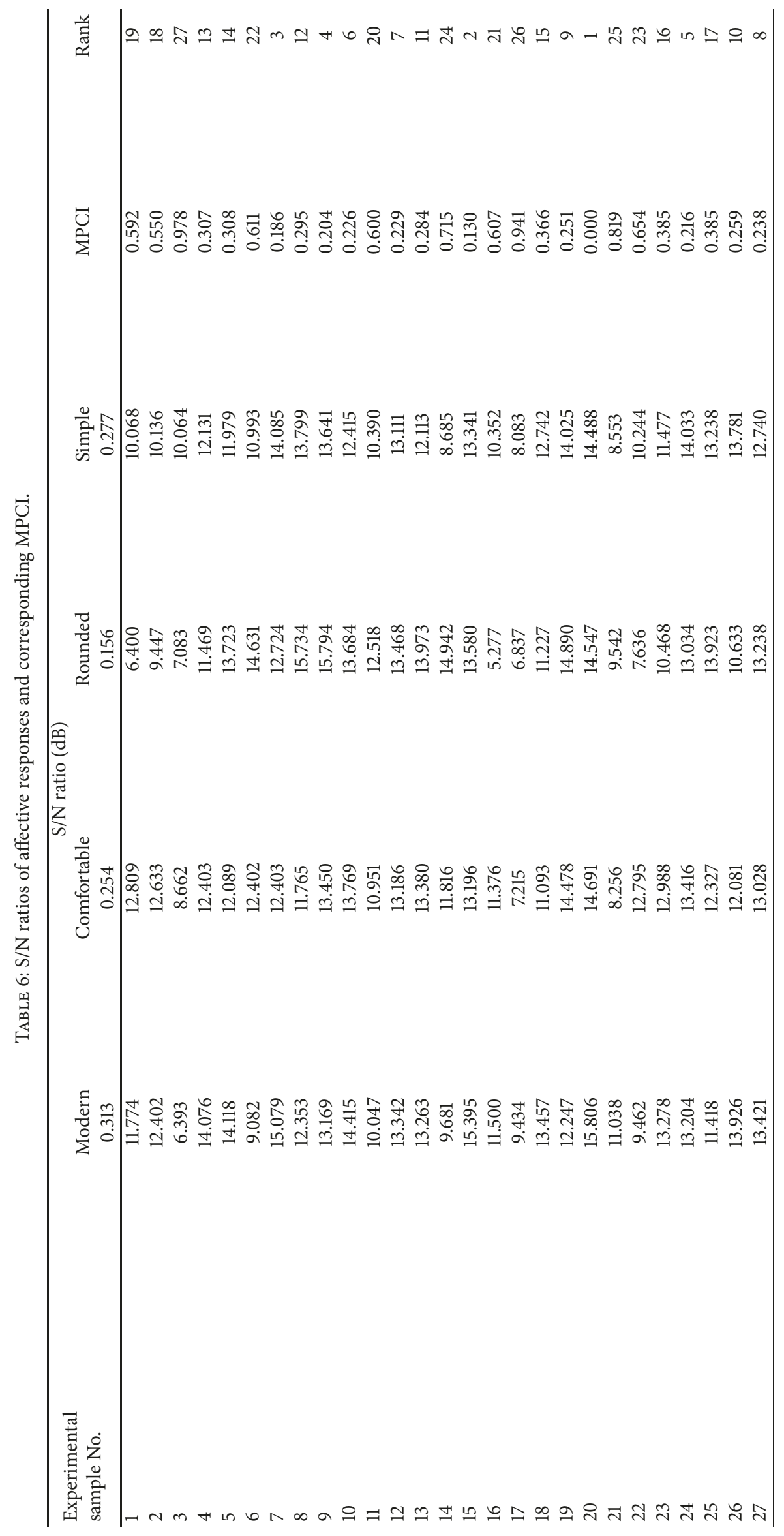


TABLE 7: Multiple answers for fuzzy affective responses.

\begin{tabular}{|c|c|c|c|c|c|}
\hline $\begin{array}{l}\text { Affective } \\
\text { Responses }\end{array}$ & $\begin{array}{l}\text { Very unimportant } \\
(\mathrm{VU})\end{array}$ & $\begin{array}{l}\text { Not important } \\
\text { (NI) }\end{array}$ & $\begin{array}{l}\text { Neutral } \\
(\mathrm{N})\end{array}$ & $\begin{array}{l}\text { Important } \\
\text { (I) }\end{array}$ & $\begin{array}{l}\text { Very important } \\
\text { (VI) }\end{array}$ \\
\hline Modern & & & & 0.50 & 0.50 \\
\hline Comfortable & & & 0.40 & 0.40 & 0.20 \\
\hline Rounded & 0.40 & 0.50 & 0.10 & & \\
\hline Simple & & & 0.20 & 0.50 & 0.30 \\
\hline
\end{tabular}

TABLE 8: Mean of MARs preferences.

\begin{tabular}{lccccc}
\hline $\begin{array}{l}\text { Affective } \\
\text { Responses }\end{array}$ & $\begin{array}{c}\text { Very unimportant } \\
(\mathrm{VU})\end{array}$ & $\begin{array}{c}\text { Not important } \\
(\mathrm{NI})\end{array}$ & $\begin{array}{c}\text { Neutral } \\
(\mathrm{N})\end{array}$ & \multicolumn{2}{c}{$\begin{array}{c}\text { Important } \\
(\mathrm{I})\end{array}$} \\
\hline Modern & 0.000 & 0.000 & 0.015 & 0.287 & $\begin{array}{c}\text { Very important } \\
(\mathrm{VI})\end{array}$ \\
Comfortable & 0.000 & 0.000 & 0.311 & 0.699 \\
Rounded & 0.069 & 0.571 & 0.320 & 0.585 & 0.040 \\
Simple & 0.000 & 0.000 & 0.104 & 0.640 & 0.000 \\
\hline
\end{tabular}

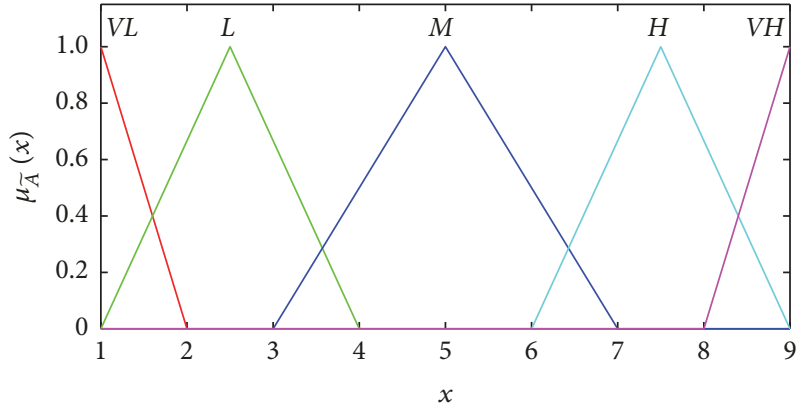

FIgURE 4: Membership functions of fuzzy linguistic terms for evaluating affective responses.

case study appear to be incomplete. This may be overcome in future studies. Furthermore, the sample size was 60 in the case study, which supports the use of statistics and interpretation of quantitative data [42]. Therefore, the number of participants was adequate; however, if this approach is applied to product design at companies, the number of participants should be determined by considering the margin of error, confidence level, and total population of the target market [43].

To integrate the multiple performance characteristics pertaining to MARs into a synthetic performance index, it is assumed that the preference weights conform to a linear mode; that is, they satisfy the additive effect and there exists no interactive effect. This approach is simple, easy, and effective for execution. Nevertheless, in practice, the affective responses used as performance characteristics for evaluation are not independent value-wise [31, 44], and the contribution of one performance characteristic of affective responses to product evaluation depends on the condition of the other performance characteristics. For example, in this case study, the MARs for car profile were "Modern," "Simple," "Rounded," and "Comfort." The contribution of "Modern, Simple, Rounded, and Comfort" may not simply be equal to the sum of the contributions of "Modern," "Simple," "Rounded," and "Comfort," and there exist interactive effects

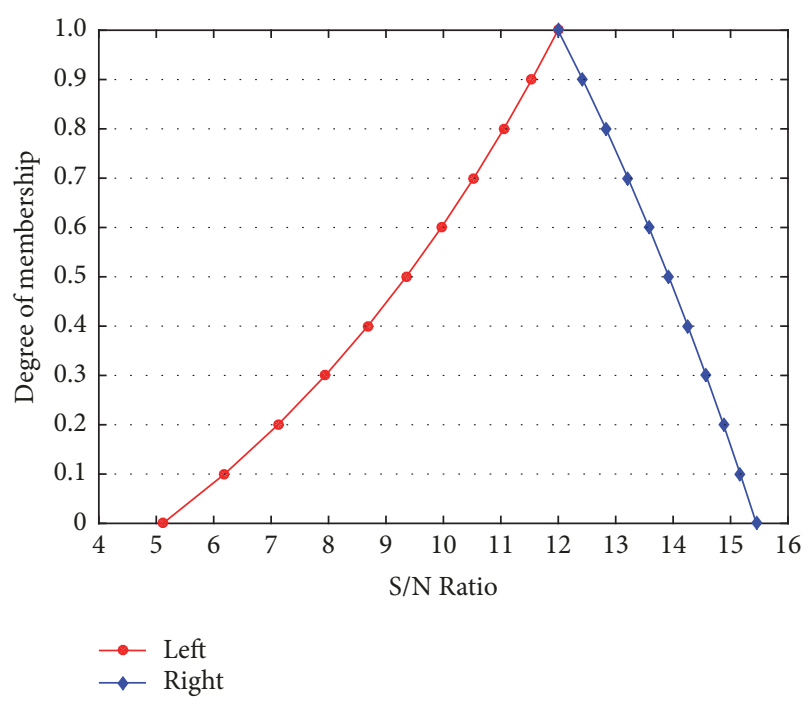

FIGURE 5: S/N ratios of fuzzy number "Medium."

among them. Future research should focus on this topic to improve the precision of MARs integration.

Although car profile design is used as an example, the proposed approach can be applied to other products with various design variables, such as mobile phones [5], digital cameras [4], and running shoes [45]. The proposed method is somewhat complicated and involves many calculation steps. However, it can be properly implemented. More importantly, the method incorporates four simplification stages, namely design analysis, Taguchi experiment, transformation of $\mathrm{S} / \mathrm{N}$ ratios, and optimization design. These simplification stages compensate for the complexity of the calculation. Therefore, the proposed method can be used as a universal robust design approach to improve product form design quality in terms of MARs.

In brief, the proposed fuzzy-based hybrid Taguchi method is useful for multiobjective optimization of product form design because it has the following advantages: 


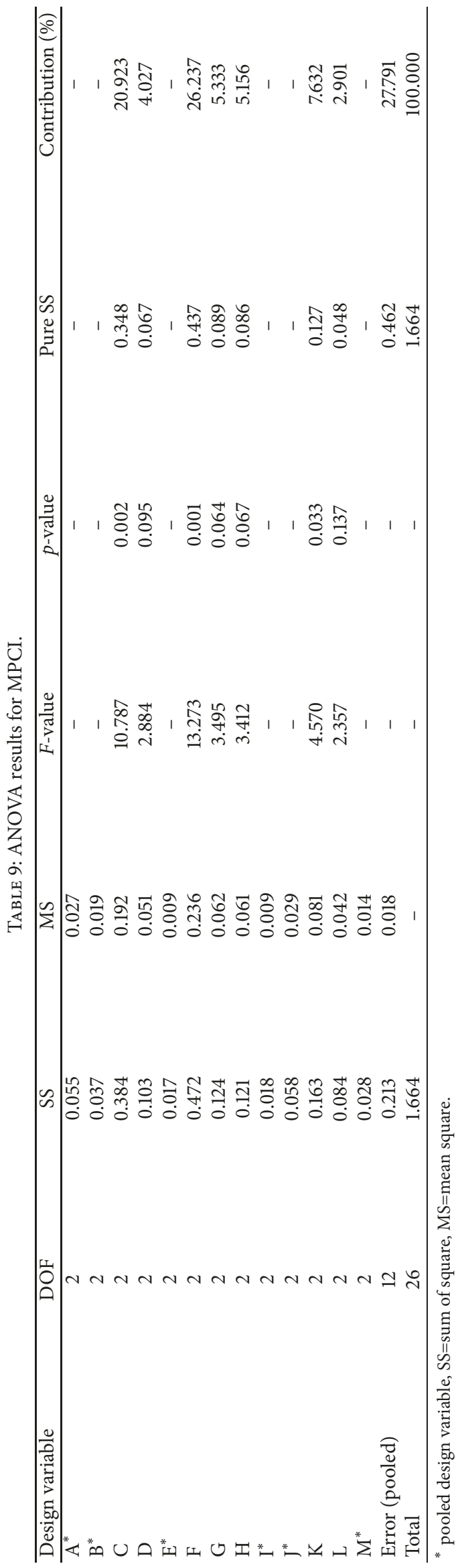




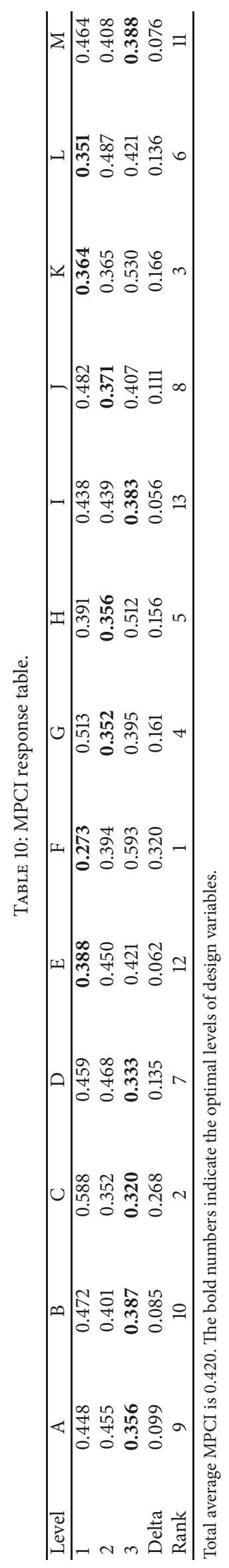


TABLE 11: Results of confirmation test.

\begin{tabular}{lccc}
\hline & $\begin{array}{c}\text { Initial design combination } \\
\text { in OA (Sample No. 1) }\end{array}$ & Competitor's design combination & $\begin{array}{c}\text { Optimal design } \\
\text { combination }\end{array}$ \\
\hline $\begin{array}{l}\text { Level } \\
\text { combination }\end{array}$ & $\mathrm{A}_{1} \mathrm{~B}_{1} \mathrm{C}_{1} \mathrm{D}_{1} \mathrm{E}_{1} \mathrm{~F}_{1} \mathrm{G}_{1} \mathrm{H}_{1} \mathrm{I}_{1} \mathrm{~J}_{1} \mathrm{~K}_{1} \mathrm{~L}_{1} \mathrm{M}_{1}$ & $\mathrm{~A}_{3} \mathrm{~B}_{1} \mathrm{C}_{3} \mathrm{D}_{2} \mathrm{E}_{2} \mathrm{~F}_{1} \mathrm{G}_{3} \mathrm{H}_{2} \mathrm{I}_{1} \mathrm{~J}_{3} \mathrm{~K}_{2} \mathrm{~L}_{1} \mathrm{M}_{3}$ & $\mathrm{~A}_{3} \mathrm{~B}_{3} \mathrm{C}_{3} \mathrm{D}_{3} \mathrm{E}_{1} \mathrm{~F}_{1} \mathrm{G}_{2} \mathrm{H}_{2} \mathrm{I}_{3} \mathrm{~J}_{2} \mathrm{~K}_{1} \mathrm{~L}_{1} \mathrm{M}_{3}$ \\
Sketch & & & \\
& & & 15.806 \\
Modern & 11.774 & 14.691 & 14.547 \\
Comfortable & 12.809 & 14.488 & 15.115 \\
Rounded & 6.400 & 59.532 & 15.874 \\
Simple & 10.068 & 3.119 & 62.651 \\
Total & 41.051 & & - \\
Improvement & 21.600 & & 136 \\
\hline
\end{tabular}

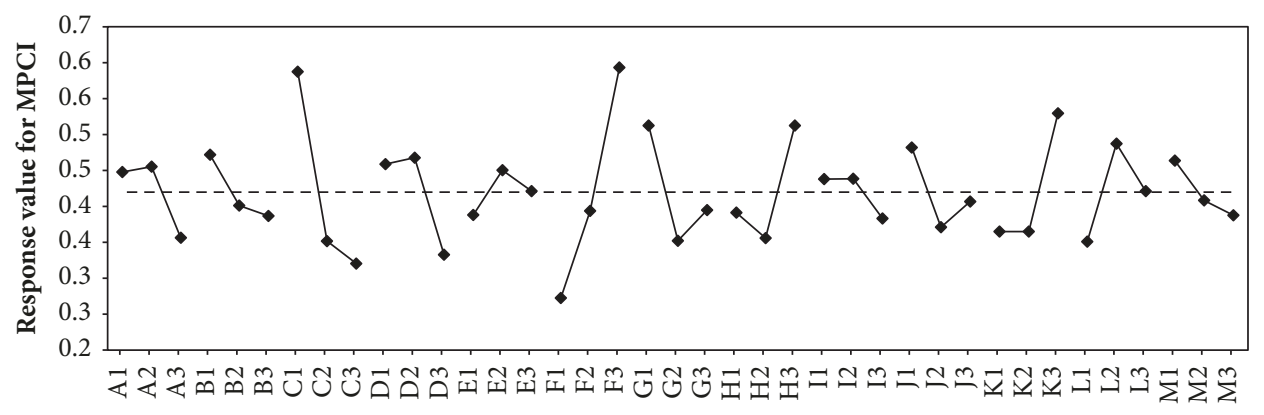

FIGURE 6: Response graph of MPCI.

(1) Compared with the traditional affective engineering method, which uses only the mean of affective response evaluations, the proposed approach uses the $\mathrm{S} / \mathrm{N}$ ratio, which considers both the mean and variation [32]. As a result, the obtained optimal product form design is more robust.

(2) The proposed approach adopts fuzzy sets to measure affective responses. Compared with the conventional method, which uses a semantic differential scale or a Likert scale, the proposed method can consider the imprecision and vagueness in the process of evaluating affective responses [13].

(3) To express preferences, a fuzzy questionnaire with multiple answers is used. In comparison with the commonly used questionnaire, which allows only a single answer [22], the proposed approach reflects consumers' preferences more accurately.

(4) Because of the use of VIKOR as an MCDM method, the proposed approach can combine all objectives into an MPCI. According to the MPCI, the optimal design can be achieved; in addition, great design insights can be obtained.

It should be mentioned that, to obtain the optimal product form design, Taguchi method can be integrated with other different methods, such as Kano $[9,10]$, grey relation analysis [9, 10], fuzzy logic [1], TOPSIS [9], and fuzzy integral [31]. The purpose of this paper is to propose a novel approach to optimize product form design, and no effort is made to perform a comparison study of the proposed approach with other approaches. In future studies, the authors will focus on making comparison studies to derive which approach is more suitable for product form design.

\section{Conclusion}

In this study, the authors propose a fuzzy-based hybrid Taguchi method to optimize product form design concerning MARs. Design analysis is performed first to determine the design variables and affective responses. A Taguchi experiment is then designed with the design variables as control factors and the affective responses as quality characteristics. Fuzzy sets are used to measure the affective responses, and a fuzzy questionnaire is used to collect consumers' preference weights for MARs. By employing VIKOR, the multiple S/N ratios obtained from the Taguchi experiment are mapped into an MPCI. On the basis of the MPCI, ANOVA is executed, and the response table and the response graph are obtained; thus, the optimized product form design, which can maximize quality and minimize variability, is determined.

The proposed approach is a robust design approach that can transform multiple performance characteristics pertaining to MARs into a single performance characteristic and, consequently, can simplify optimization problems. Moreover, this approach can provide valuable design insights. In this study, the authors have focused only on product form design; further research could integrate product form with color and material. 


\section{Conflicts of Interest}

The authors declare that there are no conflicts of interest regarding the publication of this paper.

\section{Acknowledgments}

The authors would like to express their sincere thanks to the participants for their assistance in this study. This study is supported by the MOE (Ministry of Education of the People's Republic of China) Project of Humanities and Social Sciences (Project no. 15YJCZH245).

\section{References}

[1] S. B. Sutono, S. H. Abdul-Rashid, H. Aoyama, and Z. Taha, "Fuzzy-based Taguchi method for multi-response optimization of product form design in Kansei engineering: A case study on car form design," Journal of Advanced Mechanical Design, Systems, and Manufacturing, vol. 10, no. 9, pp. 1-16, 2016.

[2] M. Nagamachi, "Kansei engineering as a powerful consumeroriented technology for product development," Applied Ergonomics, vol. 33, no. 3, pp. 289-294, 2002.

[3] S.-W. Hsiao, F.-Y. Chiu, and S.-H. Lu, "Product-form design model based on genetic algorithms," International Journal of Industrial Ergonomics, vol. 40, no. 3, pp. 237-246, 2010.

[4] F. Guo, W. L. Liu, F. T. Liu, H. Wang, and T. B. Wang, "Emotional design method of product presented in multi-dimensional variables based on Kansei Engineering," Journal of Engineering Design, vol. 25, no. 4-6, pp. 194-212, 2014.

[5] H. Jiang, C. K. Kwong, K. W. M. Siu, and Y. Liu, "Rough set and PSO-based ANFIS approaches to modeling customer satisfaction for affective product design," Advanced Engineering Informatics, vol. 29, no. 3, pp. 727-738, 2015.

[6] C. C. Chen and M. C. Chuang, "Integrating the Kano model into a robust design approach to enhance customer satisfaction with product design," International Journal of Production Economics, vol. 114, no. 2, pp. 667-681, 2008.

[7] M.-T. Tsai, H.-J. Gow, and W.-M. Lin, "Hybrid taguchi-immune algorithm for the thermal unit commitment," International Journal of Electrical Power \& Energy Systems, vol. 33, pp. 10621069, 2011.

[8] K. Ishikawa, Guide to Quality Control, Asian Productivity Organization, Tokyo, 1982.

[9] H.-C. Chang and H.-Y. Chen, "Optimizing product form attractiveness using Taguchi method and TOPSIS algorithm: A case study involving a passenger car," Concurrent Engineering Research and Applications, vol. 22, no. 2, pp. 135-147, 2014.

[10] H. C. Yadav, R. Jain, A. R. Singh, and P. K. Mishra, "Kano integrated robust design approach for aesthetical product design: a case study of a car profile," Journal of Intelligent Manufacturing, vol. 28, no. 7, pp. 1709-1727, 2017.

[11] H. H. Lai, Y. M. Chang, and H. C. Chang, "A robust design approach for enhancing the feeling quality of a product: a car profile case study," International Journal of Industrial Ergonomics, vol. 35, no. 5, pp. 445-460, 2005.

[12] A. Oztekin, A. Iseri, S. Zaim, and A. Nikov, "A Taguchi-based Kansei engineering study of mobile phones at product design stage," Production Planning and Control, vol. 24, no. 6, pp. 465474, 2013.
[13] J.-R. Chou, "A Kansei evaluation approach based on the technique of computing with words," Advanced Engineering Informatics, vol. 30, no. 1, pp. 1-15, 2016.

[14] C.-H. Wang, "Incorporating customer satisfaction into the decision-making process of product configuration: a fuzzy kano perspective," International Journal of Production Research, vol. 51, no. 22, pp. 6651-6662, 2013.

[15] A. Güran, M. Uysal, Y. Ekinci, and C. B. Güran, "An additive FAHP based sentence score function for text summarization," Information Technology and Control, vol. 46, no. 1, pp. 53-69, 2017.

[16] C.-H. Wang and J. Wang, "Combining fuzzy AHP and fuzzy Kano to optimize product varieties for smart cameras: a zeroone integer programming perspective," Applied Soft Computing, vol. 22, pp. 410-416, 2014.

[17] L. A. Zadeh, "From computing with numbers to computing with words - from manipulation of measurements to manipulation of perceptions," International Journal of Applied Mathematics and Computer Science, vol. 12, no. 3, pp. 307-324, 2002.

[18] S. Chi and L. Hsu, "A fuzzy taguchi experimental method for problems with multi-attribute quality characteristics and its application on plasma Arc welding," Journal of the Chinese Institute of Engineers, vol. 18, no. 4, pp. 97-110, 2001.

[19] S.-W. Hsiao and J.-R. Chou, "A Gestalt-like perceptual measure for home page design using a fuzzy entropy approach," International Journal of Human-Computer Studies, vol. 64, no. 2, pp. 137-156, 2006.

[20] K. D. Atalay and E. Eraslan, "Multi-criteria usability evaluation of electronic devices in a fuzzy environment," Human Factors and Ergonomics in Manufacturing \& Service Industries, vol. 24, no. 3, pp. 336-347, 2014.

[21] H. T. Nguyen and B. Wu, Fundamentals of statistics with fuzzy data, Springer, New York, 2006.

[22] Y.-C. Lee and S.-Y. Huang, "A new fuzzy concept approach for Kano's model," Expert Systems with Applications, vol. 36, no. 3, pp. 4479-4484, 2009.

[23] M. Ghorbani, S. Mohammad Arabzad, and A. Shahin, "A novel approach for supplier selection based on the kano model and fuzzy MCDM," International Journal of Production Research, vol. 51, no. 18, pp. 5469-5484, 2013.

[24] Y.-L. Lu, Y.-C. Lin, and B. Wu, "Fuzzy decision process in parental school choice," in Innovative Management in Information and Production, J. Watada, Ed., pp. 223-232, Springer New York, New York, NY, USA, 2014.

[25] S. Opricovic, Multicriteria Optimization of Civil Engineering Systems, Faculty of Civil Engineering, Belgrade, 1998.

[26] S. Opricovic and G. H. Tzeng, "Compromise solution by MCDM methods: a comparative analysis of VIKOR and TOPSIS," European Journal of Operational Research, vol. 156, no. 2, pp. 445-455, 2004.

[27] A. Shemshadi, H. Shirazi, M. Toreihi, and M. J. Tarokh, "A fuzzy VIKOR method for supplier selection based on entropy measure for objective weighting," Expert Systems with Applications, vol. 38, no. 10, pp. 12160-12167, 2011.

[28] M. Sivapragash, P. Kumaradhas, B. S. J. Retnam, X. F. Joseph, and U. T. S. Pillai, "Taguchi based genetic approach for optimizing the PVD process parameter for coating ZrN on AZ91D magnesium alloy," Materials and Corrosion, vol. 90, pp. 713-722, 2016. 
[29] H. C. Huang, S. S. Xu, and C. H. Wu, "Erratum: A hybrid swarm intelligence of artificial immune system tuned with Taguchigenetic algorithm and its field-programmable gate array realization to optimal inverse kinematics for an articulated industrial robotic manipulator," Advances in Mechanical Engineering, vol. 8, no. 5, pp. 1-10, 2016.

[30] C. Ling and G. Salvendy, "Optimizing heuristic evaluation process in E-commerce: Use of the Taguchi method," International Journal of Human-Computer Interaction, vol. 22, no. 3, pp. 271287, 2007.

[31] Y. Li and L. Zhu, "Optimisation of product form design using fuzzy integral-based Taguchi method," Journal of Engineering Design, vol. 28, no. 7-9, pp. 480-504, 2017.

[32] G. Taguchi, S. Chowdhury, and Y. Wu, Taguchi's Quality Engineering Handbook, John Wiley \& Sons, Inc, Hoboken, NJ, USA, 2005.

[33] T.-P. Dao, "Multiresponse optimization of a compliant guiding mechanism using hybrid taguchi-grey based fuzzy logic approach," Mathematical Problems in Engineering, vol. 2016, Article ID 5386893, 17 pages, 2016.

[34] L. A. Zadeh, "Fuzzy sets," Information and Computation, vol. 8, pp. 338-353, 1965.

[35] D. Pal, G. S. Mahapatra, and G. P. Samanta, "Stability and bionomic analysis of fuzzy parameter based prey-predator harvesting model using UFM," Nonlinear Dynamics, vol. 79, no. 3, pp. 1939-1955, 2014.

[36] T. Gwo-Hshiung, G. H. Tzeng, and J.-J. Huang, Multiple Attribute Decision Making: Methods and Applications, CRC Press, 2011.

[37] G. J. Klir and B. Yuan, Fuzzy Sets and Fuzzy Logic Theory and Applications, Prentice Hall, New Jersey, NJ, USA, 1995.

[38] L. Tong, C. Chen, and C. Wang, "Optimization of multi-response processes using the VIKOR method," The International Journal of Advanced Manufacturing Technology, vol. 31, no. 1112, pp. 1049-1057, 2007.

[39] H. Zimmermann, Fuzzy Set Theory-and Its Applications, Kluwer Academic, Boston, Mass, USA, 4th edition, 2001.

[40] M.-D. Shieh, Y. Li, and C.-C. Yang, "Product form design model based on multiobjective optimization and multicriteria decision-making," Mathematical Problems in Engineering, vol. 2017, Article ID 5187521, 15 pages, 2017.

[41] G. Taguchi, System of Experimental Design: Engineering Methods to Optimize Quality and Minimize Costs, UNIPUB/Kraus International Publications, New York, NY, USA, 1987.

[42] J. Sauro and J. Lewis, Quantifying the User Experience: Practical Statistics for User Research, Morgan Kaufmann, Cambridge, MA, USA, 2nd edition, 2016.

[43] G. Salvendy, Handbook of Human Factors and Ergonomics, John Wiley \& Sons, Inc, Hoboken, NJ, USA, 4th edition, 2012.

[44] N. F. Roozenburg and J. Eekels, Product Design: Fundamentals and Methods, John Wiley \& Sons Ltd, Baffins Lane, Chichester, England, 1995.

[45] M.-D. Shieh and Y.-E. Yeh, "Developing a design support system for the exterior form of running shoes using partial least squares and neural networks," Computers \& Industrial Engineering, vol. 65, no. 4, pp. 704-718, 2013. 


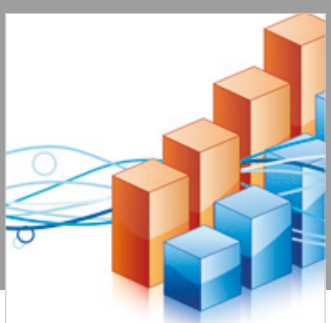

Advances in

Operations Research

\section{-n-m}
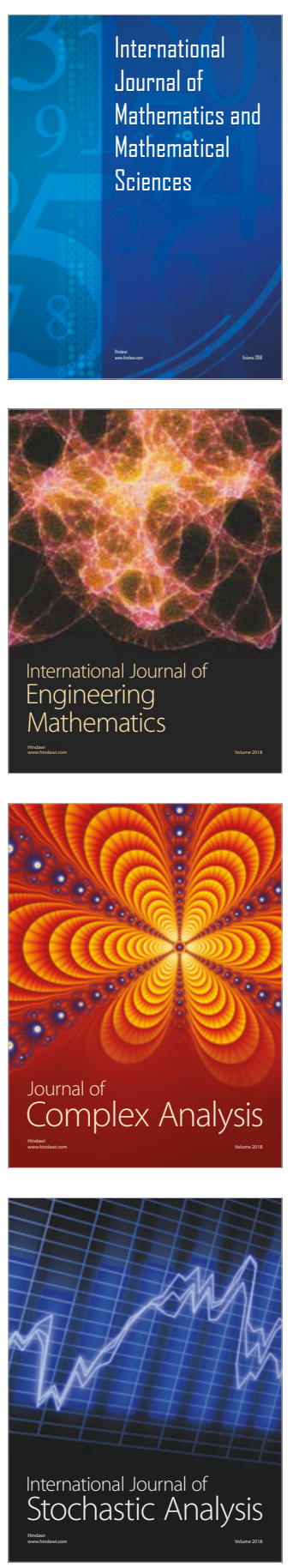
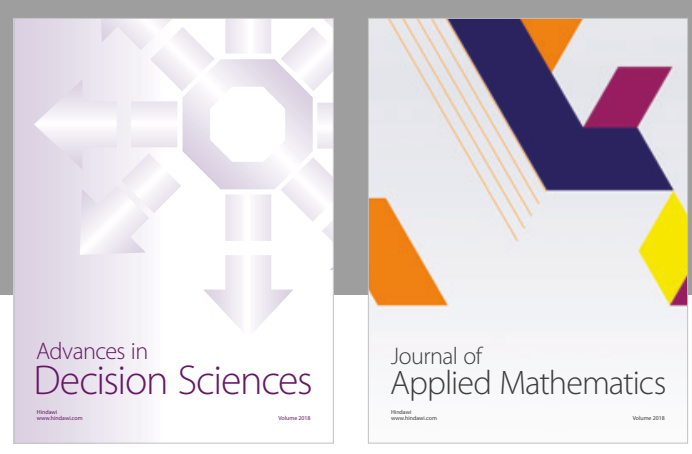

Journal of

Applied Mathematics
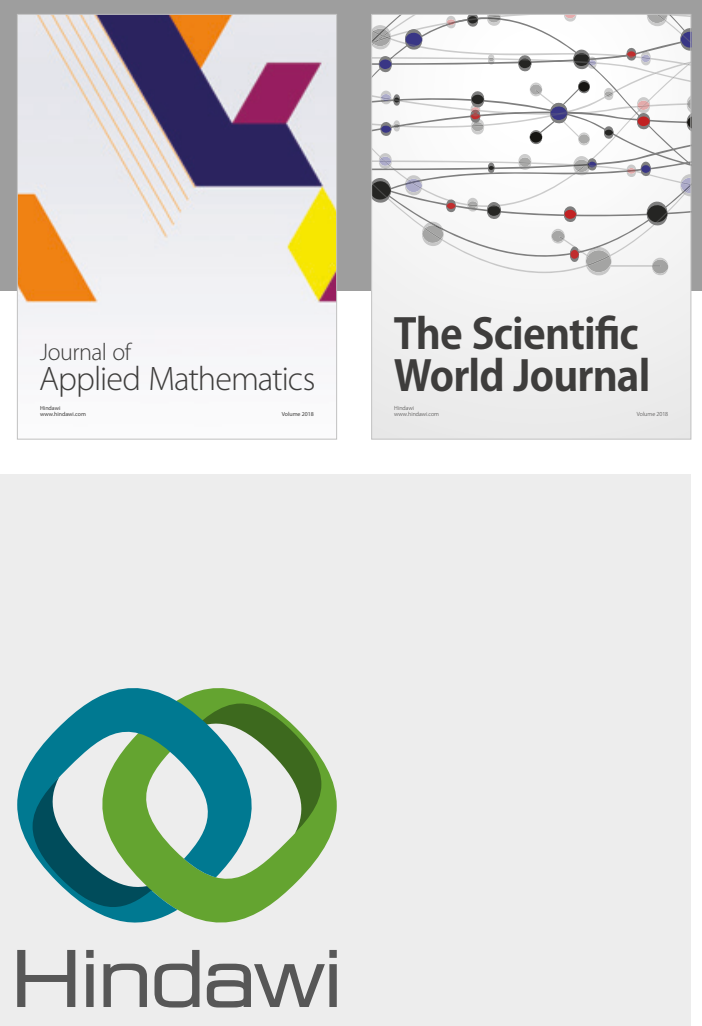

Submit your manuscripts at

www.hindawi.com

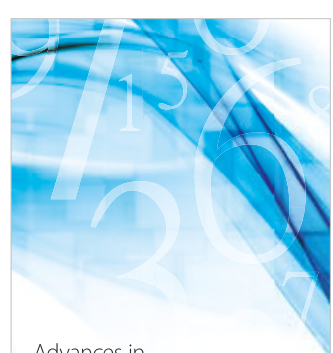

Advances in
Numerical Analysis
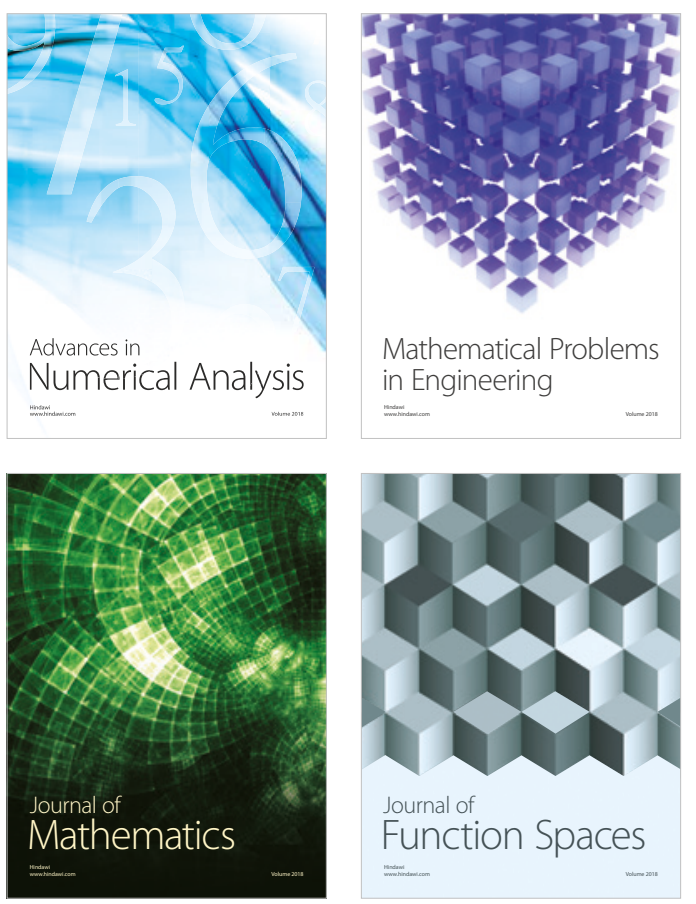

Mathematical Problems in Engineering

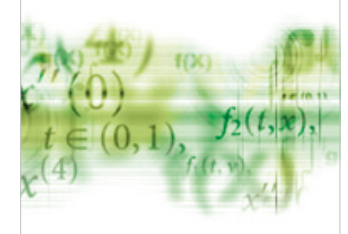

International Journal of

Differential Equations

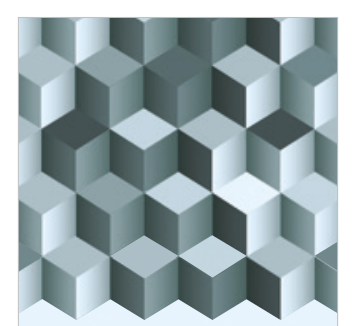

Journal of

Function Spaces

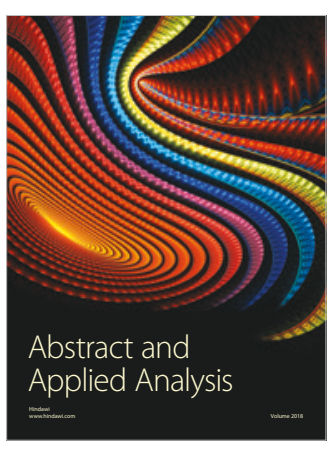

The Scientific

World Journal

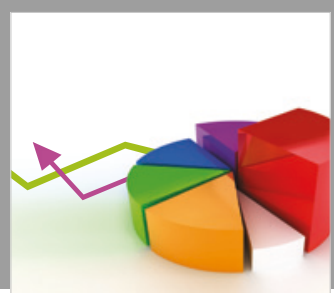

Journal of

Probability and Statistics
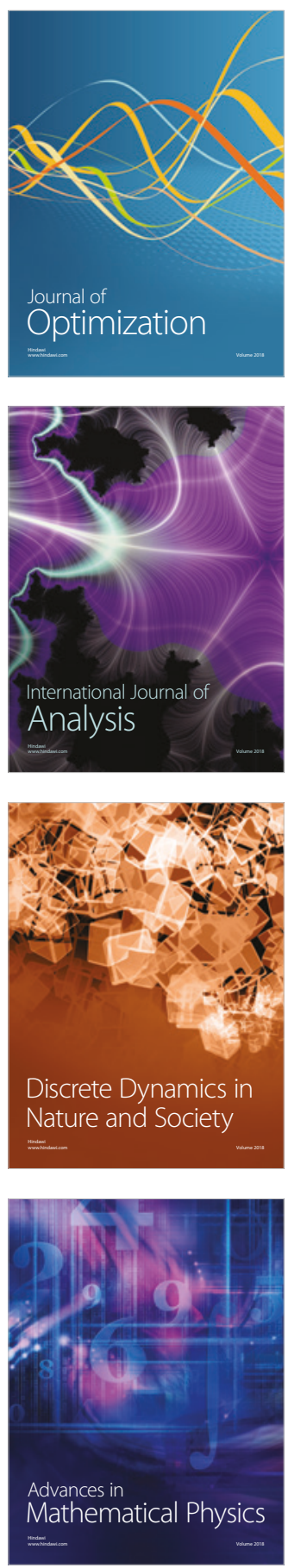